\section{Case Reports in Oncology}

\title{
Cytological Diagnosis of Plasmablastic Lymphoma Involving the Parotid Gland: A Case Report with Review of the Literature
}

\author{
Ghaleb Elyamany $^{\mathrm{a}} \quad$ Ahmed Fouly $^{\mathrm{a}}$ Abdulmalik Alqahtani ${ }^{\mathrm{a}}$ \\ Assem Alrumeh $^{a}$ Shuaa Asiri ${ }^{a}$ Salman Ali Faifi ${ }^{b}$ Saeed Alshieban ${ }^{b}$ \\ aDepartment of Central Military Laboratory and Blood Bank, Prince Sultan Military Medical \\ City, Riyadh, Saudi Arabia; 'bepartment of Pathology and Laboratory Medicine, Ministry of \\ National Guard Health Affairs, King Abdullah International Medical Research Center, King \\ Saud Bin Abdulaziz University for Health Sciences, Riyadh, Saudi Arabia
}

\author{
Keywords \\ Plasmablastic lymphoma $\cdot$ Cytology $\cdot \mathrm{HHV}-8$
}

\section{Abstract}

Plasmablastic lymphoma (PBL) is a rare subtype of non-Hodgkin's lymphoma that is associated with acquired immunodeficiency syndrome (AIDS), characterized by its association with Epstein-Barr virus (EBV), aggressive nature, and plasmacytic/plasmablastic differentiation. PBL remains a therapeutic and diagnostic challenge. Diagnosis of PBL by fine-needle aspiration cytology (FNAC) is reported infrequently. We herein describe the cytodiagnosis of a rare case of HIV-negative PBL in a 58-year-old man without EBV infection presented by parotid swelling. The current case study highlights the cytomorphologic features that may help to distinguish PBL from other mimics. However, although the cytomorphologic features may suggest $\mathrm{PBL}$, a definitive diagnosis requires additional studies including tissue biopsy and immunohistochemistry, in addition to biochemical investigations and radiological workup to establish the diagnosis and exclude similar conditions. In conclusion, FNAC is a very useful, simple, rapid and reliable procedure for diagnosis of the lymphoma. FNAC provided the earliest clue to diagnosis of PBL, which was later confirmed by tissue biopsy. @ 2021 The Author(s). 
Elyamany et al.: PBL Involving the Parotid Gland

\section{Introduction}

In the World Health Organization (WHO) classification, plasmablastic lymphoma (PBL) is considered to be a new subtype of aggressive mature B-cell neoplasm with distinct morphology, immunophenotype with plasmacytic differentiation. PBL occurs mainly in immune-compromised individuals, usually associated with human immunodeficiency virus (HIV)-positive patients. PBL was originally described in oral cavity; however, many cases are reported in extra-oral sites. Recently, dual infection with Epstein-Barr virus (EBV) and human herpesvirus 8 (HHV-8) has been demonstrated in PBL [1-3]. PBL is a diagnostic and therapeutic challenge with aggressive clinical course and poor outcome. Diagnosis of PBL by fineneedle aspiration cytology (FNAC) is reported infrequently [4].

Herein, we report a rare case of HIV-negative PBL in a 58-year-old man without EBV infection presented by parotid swelling, in which FNAC provided the earliest clue to diagnosis of PBL, which was confirmed by histology and immunohistochemistry. This case report highlights the usefulness of FNAC in diagnosis of PBL.

\section{Case Presentation}

An 58-year-old male, a known case of diabetes mellitus on treatment, presented with a swelling in the right parotid region, with a history of fever on and off for 3 months, sweating, and weight loss of $6.0 \mathrm{~kg}$. The swelling was hard in consistency and had rapidly enlarged over the past 2 weeks. The right supraclavicular lymph node swelling was also noticed after the swelling of right parotid region.

Computed tomography for chest, abdomen, and pelvis showed multiple hypodense liver lesions, bilateral small pleural effusion, right apical lung nodule, axillary mediastinal peripancreatic and retroperitoneal lymphadenopathy. Skull and spine X-ray were negative for osteolytic lesions.

Fine-needle aspiration from right parotid swelling was performed, which revealed large plasmacytoid cells with central to eccentrically placed large nuclei, with perinuclear halos, less condensed chromatin, and prominent nucleoli with abundant densely basophilic cytoplasm. Binucleated and trinucleated forms and atypical mitotic figures are noted. Also matureappearing plasma cells, scattered neutrophils, eosinophils, and apoptotic bodies were noted (Fig. 1). An initial diagnosis of PBL was made with a differential diagnosis of plasmablastic plasmacytoma/myeloma for confirmation by tissue biopsy and other workup due to overlap and similarities between both diseases and other diseases as well as diffuse large B-cell lymphoma (DLBCL) with plasmacytic differentiation.

A subsequent biopsy from right supraclavicular lymph node showed a tumour which was composed of sheets of predominantly large cells with plasmablastic, immunoblastic, or plasmacytic morphology. Also mature-appearing plasma cells and apoptotic bodies were noted (Fig. 2a). On immunohistologic study, the malignant cells were positive for CD45, CD138, CD79a, IgM, MUM1, EMA, CD38, HHV-8, and Kappa chain; they are negative for CD20, CD3, and CD56 and EBV-EBER (Fig. 2c, d). The proliferation index (Ki-67) was high. The final diagnosis was reported PBL, which confirmed the cytological diagnosis of PBL.

The laboratory findings of the patient at diagnosis showed thrombocytopenia $(90 \times$ $10^{9} / \mathrm{L}$ ), elevated lactate dehydrogenase $346 \mathrm{U} / \mathrm{L}$ (reference range 135-255), and increased $\mathrm{B}_{2}$ microglobulin $5.7 \mathrm{mg} / \mathrm{L}$ (reference range 1.09-2.53). The hepatitis and HIV screen were negative. Serum and urine protein electrophoresis revealed the absence of paraprotein or free light chains. Serum calcium and renal function were normal.

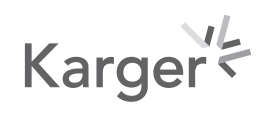




\section{Case Reports in Oncology}

Fig. 1. FNAC smear from parotid swelling showing atypical large plasmacytoid cells.

\begin{tabular}{l|l}
\hline Case Rep Oncol 2021;14:244-248 \\
\hline DOI: 10.1159/000509746 & $\begin{array}{l}\text { @ 2021 The Author(s). Published by S. Karger AG, Basel } \\
\text { www.karger.com/cro }\end{array}$ \\
\hline
\end{tabular}
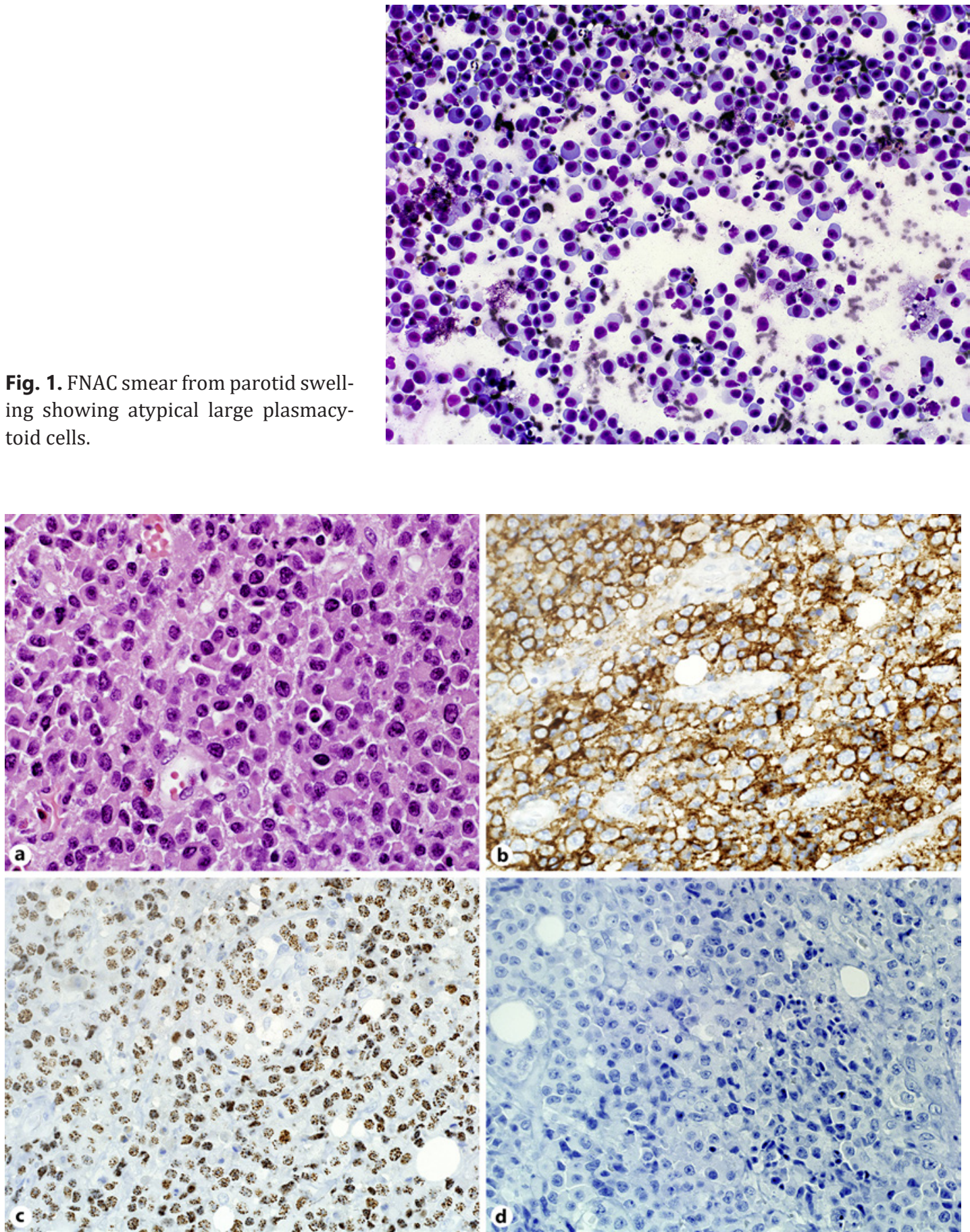

Fig. 2. a-d Histomorphologic features of lymph node biopsy. a H\&E. PBL consists of a population of large lymphoid cells showing plasmablastic or plasmacytic morphology. The malignant cells are positive for CD138 (b) and HHV-8 (c) and negative for CD56 (d).

Bone marrow aspirate and trephine biopsy were negative for involvement by lymphoma. CSF cytology and brain MRI were negative for involvement by lymphoma. The patient was started on CHOP chemotherapy with supportive measures. Unfortunately, the patient's general condition deteriorated and he died 3 months after diagnosis. 


\section{Discussion/Conculsion}

PBL remains a diagnostic challenge as the clinical and histopathological features are usually ambiguous. The diagnosis needs integration of clinical, morphological, immunophenotypic, and molecular features. The diagnosis of such neoplasms might be even more challenging in the setting of extra-oral localizations and in immunocompetent patients [5].

Our case report highlights the usefulness of FNAC in the diagnosis of PBL. FNAC provided the earliest clue to diagnosis of PBL, which was later confirmed by histology and immunohistochemistry.

Serum and urine protein electrophoresis was requested to rule out a plasmablastic myeloma, which revealed the absence of paraprotein or free light chains. Immunohistochemical staining with CD20 and CD56 was negative, while CD138 revealed a strong positivity and high Ki-67 (>75\%) among malignant cells. Based on the clinical presentation, morphology, and immunophenotype, the diagnosis of PBL was confirmed. Our case study is a rare case of PBL without HIV and EBV infection, involving the parotid gland; moreover, the tumour cells showed positivity for HHV-8, which is infrequently reported in PBL [3].

The main differential diagnoses are plasma cell neoplasm, extramedullary plasmacytoma (EMP)/myelomas with plasmablastic morphology, large B-cell lymphoma with plasmacytoid differentiation, and HHV-8-positive DLBCL, NOS. It is clinically important and critical to differentiate these diseases as the treatment is different.

EMP is very difficult to distinguish from PBL on FNAC because both show a plasmacytoid differentiation. The distinction between PBL and plasmablastic myelomas frequently depends on their clinical presentations. The detection of paraproteinaemia in blood and/or excess light chains (Bence-Jones proteins) in urine, lytic bone lesions, and hypercalcaemia or anaemia favours the diagnosis of a plasma cell myeloma over PBL [6]. HHV-8-positive DLBCL, NOS is excluded by expression of CD79a and CD138.

In addition to previously mentioned lymphomas, PBL should be included in the differential diagnosis of any high-grade malignant neoplasm with plasmablastic morphology. In our case involving the parotid gland, PBL should be differentiated from poorly differentiated salivary gland carcinoma, metastatic malignant melanoma, or a plasmacytoid variant of a myoepithelial neoplasm [7].

To our knowledge, there are few previous case reports [4, 7-10] describing cytological findings of a neoplasm with some similarities to the current case study; however, the current case study is unique and may be the first case report being negative for HIV and EBV and positive for HHV-8 and presented by parotid swelling as an initial presentation.

In summary, although no cytological feature is diagnostic of PBL, certain cytomorphologic features should raise suspicion and provide the earliest clue to diagnosis of PBL such as hypercellular smears with abundance of plasmablastic cells. Although these findings may suggest PBL, a definitive diagnosis requires additional studies including tissue biopsy, immunohistochemistry, and flow cytometry.

\section{Acknowledgments}

The authors thank the histopathology staff, PSMMC, Riyadh for help in this study.

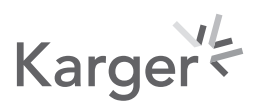




\section{Case Reports in Oncology}

Case Rep Oncol 2021;14:244-248

\begin{tabular}{l|l}
\hline DOI: $10.1159 / 000509746$ & c 2021 The Author(s). Published by S. Karger AG, Basel
\end{tabular} www.karger.com/cro

Elyamany et al.: PBL Involving the Parotid Gland

\section{Statement of Ethics}

The patient's written informed consent to publish the case was taken. The study protocol was approved by the institute's committee on human research.

\section{Conflict of Interest Statement}

The authors declare that there is no conflict of interests regarding the publication of this paper.

\section{Funding Sources}

None.

\section{Author Contributions}

All authors contributed equally. All authors have read and approved the final version of the manuscript.

\section{References}

1 Delecluse HJ, Anagnostopoulos I, Dallenbach F, Hummel M, Marafioti T, Schneider U, et al. Plasmablastic lymphomas of the oral cavity: a new entity associated with the human immunodeficiency virus infection. Blood. 1997;89(4):1413-20.

2 Witte HM, Hertel N, Merz H, Bernd HW, Bernard V, Stölting S, et al. Clinicopathological characteristics and MYC status determine treatment outcome in plasmablastic lymphoma: a multi-center study of 76 consecutive patients. Blood Cancer J. 2020;10(5):63.

3 Verma S, Nuovo GJ, Porcu P, Baiocchi RA, Crowson AN, Magro CM. Epstein-Barr virus- and human herpesvirus 8-associated primary cutaneous plasmablastic lymphoma in the setting of renal transplantation. J Cutan Pathol. 2005;32(1):35-9.

4 Patne SC, Kumar M, Khanna R. Cytodiagnosis of the primary breast lymphoma in a young woman. J Cytol. 2013; $30(4): 284-6$.

5 Elyamany G, Alzahrani AM, Aljuboury M, Mogadem N, Rehan N, Alsuhaibani O, et al. Clinicopathologic features of plasmablastic lymphoma: Single-center series of 8 cases from Saudi Arabia. Diagn Pathol. 2015;10:78.

6 Pai K, Rao L. The cytological diagnosis of extra-oral plasmablastic lymphoma: a rare entity. J Clin Diagn Res. 2013;7(4):721-2.

7 Bishop JA, Westra WH. Plasmablastic lymphoma involving the parotid gland. Head Neck Pathol. 2010;4(2): 148-51.

8 Lin F, Zhang K, Quiery AT Jr., Prichard J, Schuerch C. Plasmablastic lymphoma of the cervical lymph nodes in a human immunodeficiency virus-negative patient: a case report and review of the literature. Arch Pathol Lab Med. 2004;128(5):581-4.

9 Lin 0, Gerhard R, Zerbini MC, Teruya-Feldstein J. Cytologic features of plasmablastic lymphoma. Cancer. 2005; 105(3):139-44.

10 Reid-Nicholson M, Kavuri S, Ustun C, Crawford J, Nayak-Kapoor A, Ramalingam P. Plasmablastic lymphoma: Cytologic findings in 5 cases with unusual presentation. Cancer. 2008;114(5):333-41. 